\title{
Quantifying the Relevance of Cyclones for Precipitation Extremes
}

\section{Journal Article}

Author(s):

Pfahl, Stephan (D); Wernli, Heini (1)

Publication date:

2012-10

Permanent link:

https://doi.org/10.3929/ethz-b-000057303

Rights / license:

In Copyright - Non-Commercial Use Permitted

Originally published in:

Journal of Climate 25(19), https://doi.org/10.1175/JCLI-D-11-00705.1 


\title{
Quantifying the Relevance of Cyclones for Precipitation Extremes
}

\author{
Stephan Pfahl AND HeIni WeRnLi \\ Institute for Atmospheric and Climate Science, ETH Zurich, Zurich, Switzerland
}

(Manuscript received 30 November 2011, in final form 29 March 2012)

\begin{abstract}
Owing to the huge potential impact of precipitation extremes on society, it is important to better understand the mechanisms causing these events, and their variations with respect to a changing climate. In this study, the importance of a particular category of weather systems, namely cyclones, for the occurrence of regional-scale precipitation extremes is quantified globally using the ECMWF Interim reanalysis (ERA-Interim) dataset. Such an event-based climatological approach complements previous case studies, which established the physical relationship between cyclones and heavy precipitation. A high percentage of precipitation extremes is found to be directly related to cyclones. Regional hot spots are identified where this percentage of cycloneinduced precipitation extremes exceeds $80 \%$ (e.g., in the Mediterranean region, Newfoundland, near Japan, and over the South China Sea). The results suggest that in these regions changes of heavy precipitation with global warming are specifically sensitive to variations in the dynamical forcing, for example, related to shifts of the storm tracks. Furthermore, properties of cyclones causing extreme precipitation are investigated. In the exit regions of the Northern Hemisphere storm tracks, these cyclones are on average slightly more intense than low pressure systems not associated with precipitation extremes, but no differences with respect to minimum core pressure are found in most other parts of the midlatitudes. The fundamental linkage between cyclones and precipitation extremes may thus provide guidance to forecasters involved in flood prediction, but it is unlikely that forecasting rules based on simple cyclone properties can be established.
\end{abstract}

\section{Introduction}

Heavy precipitation and associated floods can have a major impact on society (Easterling et al. 2000; Rappaport 2000; Pall et al. 2011). Understanding mechanisms behind these extreme events is important for improving forecasting capabilities of the events and for estimating their frequency and intensity in a changing climate. The latter aspect is often addressed using fundamental thermodynamic arguments. According to these arguments, global-scale precipitation extremes are thought to intensify under global warming at a rate on the same order that atmospheric humidity increases, that is, faster than mean precipitation (Allen and Ingram 2002; Trenberth et al. 2003; Pall et al. 2007; Allan and Soden 2008). In addition to the atmospheric moisture content, variations in the lapse rate and vertical wind velocity are crucial for the exact magnitude of this intensification

Corresponding author address: Stephan Pfahl, Institute for Atmospheric and Climate Science, ETH Zurich, Universitaetstrasse 16, 8092 Zurich, Switzerland.

E-mail: stephan.pfahl@env.ethz.ch
(O'Gorman and Schneider 2009a,b). On regional scales, changes in circulation regimes and moisture convergence are also important and can modulate the response of heavy precipitation to climate change (Meehl et al. 2005; Maraun et al. 2011). Both vertical motions and regional flow patterns are governed by atmospheric dynamics. For understanding and estimating regional changes of precipitation extremes, it is thus essential to take this link to the dynamical and meteorological forcing mechanisms into account.

The influence of large-scale circulation patterns such as ENSO on precipitation extremes is evident from a statistical perspective (Kenyon and Hegerl 2010; Yiou and Nogaj 2004) but difficult to understand mechanistically. In contrast, the life cycle of synoptic flow features like low pressure systems is directly linked to the formation of precipitation. For instance, extratropical cyclones induce a poleward moisture transport along sloping moist isentropes, leading to a lifting of air masses and the formation of clouds and precipitation (Browning 1986; Wernli and Davies 1997). Therefore, cyclones are typically associated with substantial surface precipitation (Field and Wood 2007) and can cause extreme 
precipitation and flooding, as shown in many case studies (e.g., Rappaport 2000; Kahana et al. 2002; Ulbrich et al. 2003, among others). However, the contribution of cyclones to precipitation extremes has not yet been quantified climatologically and on the global scale. Recent studies investigated concurrent variations in the occurrence of cyclones and (extreme) precipitation with changing climate using correlation analysis (Raible et al. 2007; Lionello and Giorgi 2007) or explored changes in simulated extremes of precipitation accumulated over cyclone tracks (Bengtsson et al. 2009; Champion et al. 2011). In this study, the relationship between cyclones and regional-scale precipitation extremes under presentday climate conditions is analyzed in an event-based manner, using single precipitation extremes with a spatial scale of roughly $10000 \mathrm{~km}^{2}$ as a starting point. The question of how many of these extremes, defined as exceedance of the 99th percentile of precipitation at a given location, concur with the passage of a cyclone is addressed. In this way, it is possible to locally quantify the relevance of the causal relationship between cyclones and precipitation extremes.

In section $2 \mathrm{a}$, the data used in this study will be described. In addition to the European Centre for MediumRange Weather Forecasts Interim reanalysis (ERAInterim), satellite-based precipitation estimates are applied as a reference for the precipitation extremes. Subsequently, section $2 \mathrm{~b}$ will introduce the method that is used for relating precipitation extremes to cyclones, and section $2 \mathrm{c}$ will describe a corresponding significance test. Results of the comparison of ERA-Interim and satellite-based precipitation data as well as the average cyclone distribution will be presented in sections $3 \mathrm{a}$ and $3 \mathrm{~b}$, respectively. The main result of this study showing the relevance of cyclones for precipitation extremes will then be presented and discussed in section 3c. Section $3 \mathrm{~d}$ will briefly analyze the characteristics of cyclones associated with extreme precipitation. Finally, conclusions and an outlook on future research will be given in section 4 .

\section{Data and methods}

\section{a. Reanalysis data and CMORPH precipitation estimates}

For studying the link between cyclones and extreme precipitation, ERA-Interim data (Dee et al. 2011) from the European Centre for Medium-Range Weather Forecasts for the years 1989-2009 are employed. The advantage of using reanalysis data is that they are globally available with high, 6-hourly time resolution and that the circulation patterns (including cyclones) are well constrained by observations. Six-hourly global fields of sea level pressure (SLP) and prognostic precipitation are obtained from the ERA-Interim dataset. For precipitation, forecast steps from 6 to 12 and 12 to $18 \mathrm{~h}$ are used, neglecting the first six hours of a forecast because of potential model spinup. All data, which are originally available with a T255 spectral resolution, are interpolated to a $1^{\circ} \times 1^{\circ}$ latitude-longitude grid. At each grid point, the 99th percentile of 6-hourly accumulated precipitation is calculated and all 6-h periods with precipitation larger than this percentile are identified as extreme events. This leads to 306 events per grid point, which is a compromise between statistical robustness (which would increase if a slightly lower percentile was used) and numerical feasibility (since all analyses are done on a gridpoint basis, a lot of data have to be processed). ERA-Interim precipitation values represent an average over model grid boxes, and the extremes thus differ in magnitude from those measured at stations (Dulière et al. 2011). Therefore, the focus of this study is on the investigation of extreme precipitation events that are not restricted to local scales, but occur in areas of at least $10000 \mathrm{~km}^{2}$ (roughly the size of a $1^{\circ} \times 1^{\circ}$ grid box) and potentially cause floods also in larger rivers.

Since ERA-Interim precipitation is obtained from short-term model forecasts, it is affected by forecast errors. It is not a priori clear if the ERA-Interim extreme events are sufficiently realistic to be used for further, process-oriented analyses. This is checked by comparing the reanalysis data with the satellite observation-based Climate Prediction Center morphing method (CMORPH) dataset (Joyce et al. 2004) for the overlapping period from 2003 to 2009. The CMORPH data comprise precipitation estimates with high spatial and temporal resolution, obtained from a combination of microwave and infrared satellite observations. The data are available for latitudes between $60^{\circ} \mathrm{S}$ and $60^{\circ} \mathrm{N}$ since December 2002. They have been validated against station observations from North America and Australia by Joyce et al. and showed an improved performance compared to other blending techniques based on similar satellite measurements. It should nevertheless be kept in mind that the representation of extreme precipitation events in this satellite-based dataset has not yet been systematically evaluated and that the associated uncertainties are thus largely unknown. Here, 3-hourly accumulated CMORPH precipitation estimates for the years $2003-09$ on a $0.25^{\circ} \times 0.25^{\circ}$ spatial grid are used. These data are further aggregated to 6-hourly time intervals and a $1^{\circ} \times 1^{\circ}$ latitude-longitude grid for comparison with the reanalyses. As for the ERAInterim data, extreme precipitation events are defined as exceedances of the local 99th percentile, leading to 102 events per grid point. Snow or ice at the surface 
cause missing values in the CMORPH precipitation estimates (see Joyce et al. 2004). All grid points are excluded from the analysis where more than $1 \%$ of the data are missing. To compare the two datasets, ERAInterim precipitation extremes are recalculated using only data from 2003 to 2009 for the computation of the percentiles. Two extreme events in the ERA-Interim and CMORPH data are counted as simultaneous if the CMORPH event occurs with no more than a 6-h time difference from the ERA-Interim event in the same or one of the eight surrounding grid boxes. These small temporal and spatial offsets are allowed to minimize the influence of minor forecast errors on the comparison.

\section{b. Cyclone identification and matching with precipitation extremes}

From the ERA-Interim SLP fields, cyclones are detected with a slightly improved version of the algorithm introduced by Wernli and Schwierz (2006). This algorithm has the advantage that cyclones are identified as two-dimensional features with a certain spatial extent without any a priori assumptions on the cyclone radius. Local minima of SLP are detected, and a cyclone is defined as the area enclosed by the outermost closed SLP contour that contains one or several such minima. The SLP contours are identified at intervals of $0.5 \mathrm{hPa}$. The maximum length of the outermost closed contour is limited to $7500 \mathrm{~km}$. Only SLP minima at grid points with altitude below $1500 \mathrm{~m}$ are used so as to neglect spurious SLP minima caused by extrapolation to sea level. In addition, cyclones are neglected for which the SLP difference between the minimum and the outermost contour is less than $1 \mathrm{hPa}$. For cyclone tracking, temporally successive SLP minima within a given search area are connected, taking into account the previous trajectory of the system. The dimensions of the search area are $700 \mathrm{~km}$ in the direction along the previous cyclone track segment, and $400 \mathrm{~km}$ in the perpendicular direction.

Precipitation extremes, accumulated over a 6-hourly time interval, are assumed to be affected by a cyclone if the respective grid point falls within a low pressure system either at the start or at the end of the 6-hourly period. In this way, only the local influence of the low pressure system is taken into account and, for example, potential effects of trailing cold fronts or spatially shifted, but associated troughs are not considered. The slight temporal smoothing of the cyclone fields induced by this comparison approach is also considered when calculating the relative cyclone frequency, which is obtained by dividing the number of 6-hourly periods affected by a low pressure system (either at the start or at the end of the period) $N_{\text {cyc }}$ by the total number of 6-hourly intervals $N$ in the analysis period. The percentage $f$ of precipitation extremes coinciding with a cyclone is calculated as $f=$ $100 N_{\text {cyc }}^{\text {ex }} / N^{\text {ex }}$, where $N_{\text {cyc }}^{\text {ex }}$ denotes the number of extreme precipitation events occurring simultaneously (in the same 6-hourly time interval) with a low pressure system at the same grid point, and $N^{\mathrm{ex}}=306$ is the total number of precipitation extremes.

To investigate how the influence of cyclones on precipitation extremes depends on the time scale of the latter, precipitation time series are smoothed with a 1-day or 3-day running mean, centered around each 6-hourly interval. Extremes of these smoothed time series are then identified as described above (retaining the 6-hourly time granularity so as not to change the number of extreme events). At a given grid point, a precipitation extreme is associated with a cyclone if a low pressure system is present at least at one of the 6-hourly time instants in the respective 1-day or 3-day period. This by construction leads to larger cyclone frequencies and larger values of $f$ compared to the original 6-hourly intervals. Furthermore, the seasonal cycle of the relevance of cyclones for extreme precipitation events is explored. Seasonal ERA-Interim precipitation extremes are identified by calculating the 99th percentile of 6-hourly accumulated precipitation separately for the two seasons from December to February (DJF) and June to August (JJA), leading to 75 events per grid box in DJF and 77 events in JJA. The seasonal percentage of events associated with a cyclone is then calculated as outlined above.

All analyses described up to here use the extreme precipitation events as a starting point. In contrast, when starting from the cyclones affecting a specific grid box, the question can be asked: how many of these cyclones cause a precipitation extreme at this location? For this type of investigation, cyclones have to be tracked in time, because one low pressure system may be present at a given location during several 6-hourly intervals. Note again that our identification algorithm considers cyclones as features with a finite size, determined by the outermost closed SLP contour. As a consequence, at any given time a particular low pressure system affects several grid points. All cyclone tracks touching a specific point at least once during their lifetime are associated with this point. Since this assignment of grid points and cyclone tracks is computationally elaborate, it is only done for every fifth point in latitude-longitude direction. The percentage $\tilde{f}$ of cyclone tracks causing precipitation extremes is calculated as $\tilde{f}=100 \tilde{N}_{\text {cyc }}^{\mathrm{ex}} / \tilde{N}_{\mathrm{cyc}}$, where $\tilde{N}_{\text {cyc }}$ denotes the total number of cyclone tracks affecting a grid point and $\tilde{N}_{\text {cyc }}^{\text {ex }}$ is the number of such tracks concurring with a precipitation extreme at the same point during at least one 6-hourly period. Finally, cyclone properties like minimum core pressure, lifetime, and geographical aspects of the cyclone track are 
compared between cyclones causing extreme precipitation events and all other systems.

\section{c. Significance test}

If cyclones and precipitation extremes are statistically unrelated, the extreme events can be regarded as a random sample of all 6-hourly time intervals in the period, meaning that $E\left(N_{\text {cyc }}^{\text {ex }} / N^{\text {ex }}\right)=N_{\text {cyc }} / N$ [where $E(\ldots)$ denotes the expected value]; that is, $f$ is similar to the relative cyclone frequency. In contrast, in regions where $f$ is distinctly larger than the relative cyclone frequency, cyclones are dynamically highly relevant for producing precipitation extremes.

To detect grid points where the relationship between cyclones and precipitation extremes is statistically not significant, a bootstrap test based on random allocations is performed. The occurrence of cyclones at selected base grid points is compared to randomly chosen precipitation events so as to obtain statistical distributions of matches between cyclones and precipitation extremes that occur purely by chance. Since the precipitation events should be physically unrelated to cyclones at the base locations, they are taken from grid points from the opposite hemisphere. Technically, the significance test works as follows: (i) 600 base grid points poleward of $20^{\circ}$ latitude are randomly chosen, with average cyclone frequencies evenly distributed over the range from $0 \%$ to $60 \%$. (ii) For every base grid point, 1000 event lists are constructed, consisting of 306 precipitation extremes each (306 is the number of extreme events identified at each point). Every event list is obtained by combining 51 successive extreme events from six points from the opposite hemisphere. This procedure is chosen so as to preserve the temporal autocorrelation properties of the precipitation extremes. (iii) For every base point the matches are counted between the occurrence of cyclones at the base point and the precipitation events from the constructed list. In this way, 600 statistical distributions of random matches between cyclones and precipitation extremes are obtained. In Fig. 1, the medians of these distributions are plotted against the cyclone frequency at the respective base grid points. They align nicely along the one-to-one line, indicating that $f$ is similar to the relative cyclone frequency if cyclones and precipitation extremes are statistically unrelated, as noted above. The 1st and 99th percentiles of the distributions as a function of cyclone frequency are obtained from a quantile regression using the FrischNewton interior point method (Portnoy and Koenker 1997; Koenker 2011) and are plotted as dashed lines in Fig. 1. Finally, the relationship between cyclones and precipitation extremes at an arbitrary grid point is considered as statistically not highly significant if the

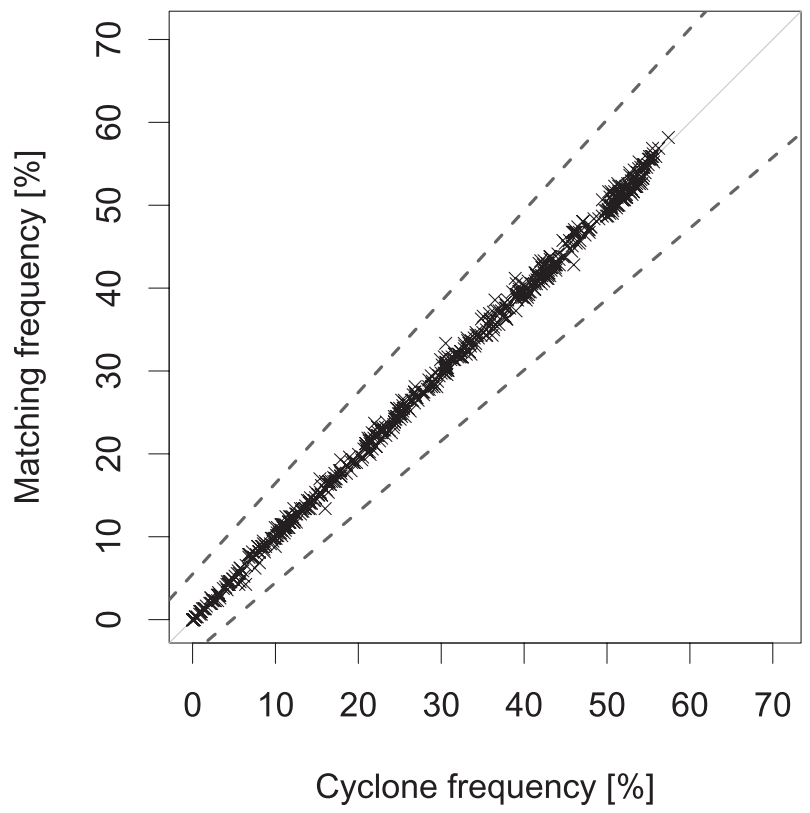

FIG. 1. Statistical distributions of matching frequencies of randomly constructed precipitation time series and cyclone time series at selected grid points. Medians (black crosses) and fitted 1st and 99th percentiles (dashed lines, obtained from a quantile regression) are plotted against the cyclone frequency at the respective grid points.

percentage $f$ of extreme events associated with a cyclone lies in between these dashed lines. For instance, at a grid point with a climatological cyclone frequency of $30 \%$, matching percentages $f$ between $21.6 \%$ and $38.4 \%$ are regarded as not significant. For the analysis of the temporally smoothed time series and the seasonal data, the same bootstrap approach is adopted.

\section{Results and discussion}

\section{a. Comparison of precipitation extremes from different datasets}

The magnitudes of the precipitation extremes from ERA-Interim and the CMORPH dataset, quantified in terms of the gridpoint-based 99th percentiles of 6-hourly accumulated precipitation, agree rather well in the extratropics poleward of approximately $30^{\circ}$ latitude (see Fig. 2). However, in many regions in the tropics the magnitude of the ERA-Interim extremes is strongly underestimated compared to the CMORPH values. Nevertheless, for our study, which investigates the temporal coincidence with cyclones, it is not the magnitude but the timing of the precipitation events that is most crucial. To evaluate this timing, the relative fraction of precipitation extremes that occur simultaneously in both datasets is determined, allowing small temporal and spatial offsets 
a

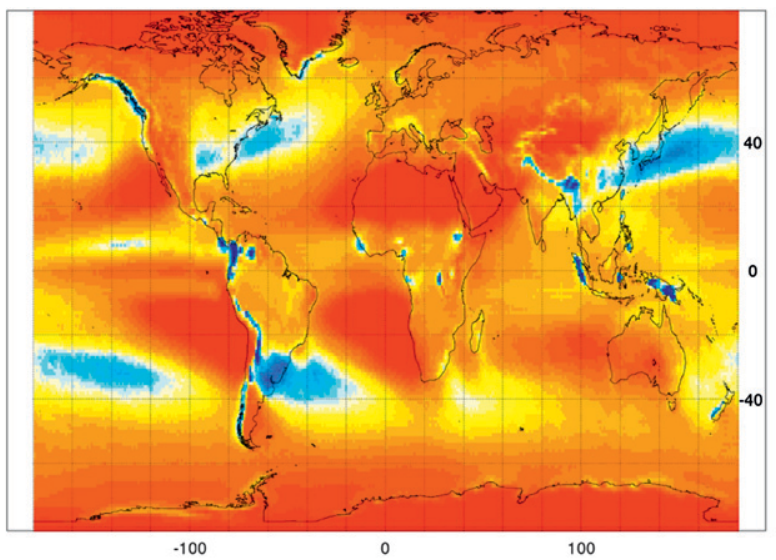

100 b

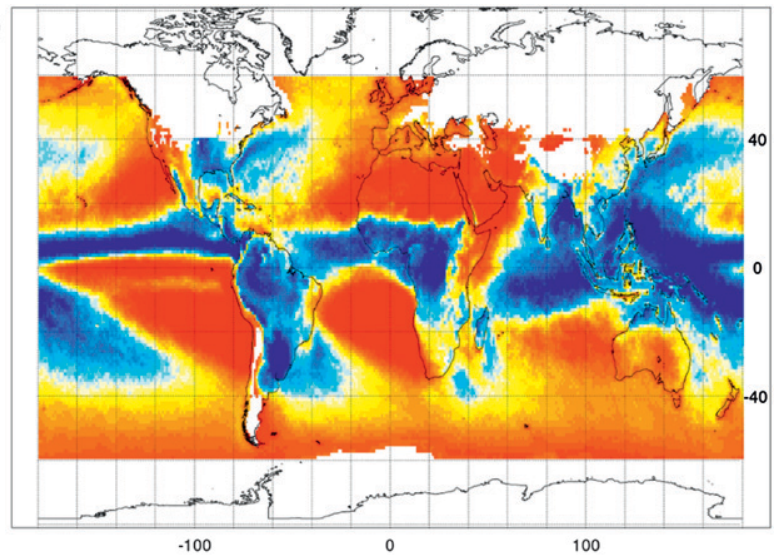

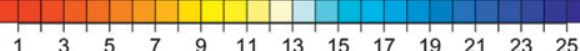

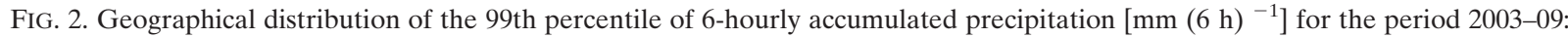
(a) 99th percentile from ERA-Interim data and (b) 99th percentile from CMORPH precipitation estimates. All data have been interpolated to $1^{\circ} \times 1^{\circ}$ latitude-longitude grid. Grid points with more than $1 \%$ missing values in the CMORPH dataset are masked in white.

(see section 2a). This relative fraction of simultaneous extreme precipitation events is shown in Fig. 3. The largest coincidence of events from the two datasets is found in the subtropics and midlatitudes, with mostly more than $70 \%$ and in certain areas more than $90 \%$ of simultaneous precipitation extremes. There are some regions, for example, over North America and at higher latitudes close to $60^{\circ}$ where the coincidence is slightly reduced. Particularly in the more poleward areas, this might relate to reduced accuracy of the satellite data, for example, owing to the availability of data from the Tropical Rainfall Measuring Mission only equatorward of $38^{\circ}$ (see again Joyce et al. 2004). Unfortunately, there are many missing values in several continental CMORPH precipitation time series in midlatitudes, prohibiting the comparison in these regions. In the tropics, where deep convection is the key process for intense precipitation, the frequency of simultaneous events is lower, around $50 \%$, with minima over land below $20 \%$. Such convective events are not explicitly simulated in the ECMWF model, but represented by a parameterization and thus less accurately captured than larger-scale precipitation in the extratropics. This seems to be particularly relevant over land areas. Overall this comparison shows that the timing of ERA-Interim precipitation extremes agrees well with satellite observations in the major part of the extratropics. The reanalysis dataset is thus well suited for analyzing the relationship between precipitation extremes and low pressure systems in these regions. Nevertheless, some uncertainty remains because ERA-Interim data cannot be evaluated poleward of $60^{\circ}$ and over certain continental areas owing to the lack of CMORPH observations.

\section{b. Cyclone frequency}

Figure $4 \mathrm{a}$ shows the relative frequency of cyclones identified from the ERA-Interim SLP fields for the analysis period 1989-2009. This relative cyclone frequency has regional maxima of $40 \%-60 \%$ in the North Atlantic, North Pacific, and Southern Hemisphere storm track regions, as well as over land close to high mountain areas. The latter might be influenced by inaccuracies in the computation of sea level pressure over high

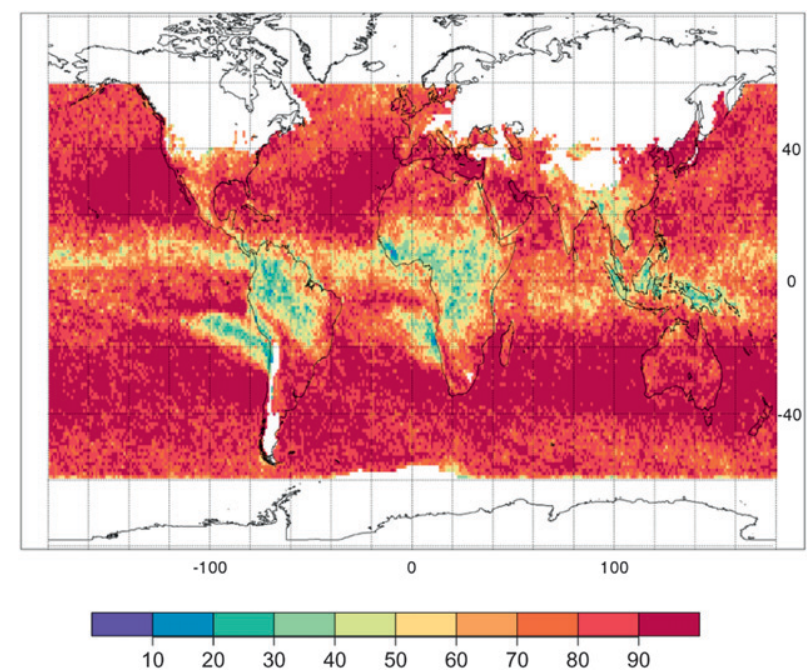

FIG. 3. Coincidence of extreme precipitation events in reanalysis and satellite data. Relative fraction (\%) of simultaneous 6-hourly precipitation extremes in ERA-Interim and CMORPH during 2003-09. Grid points with more than $1 \%$ missing values in the CMORPH dataset are masked in white. 


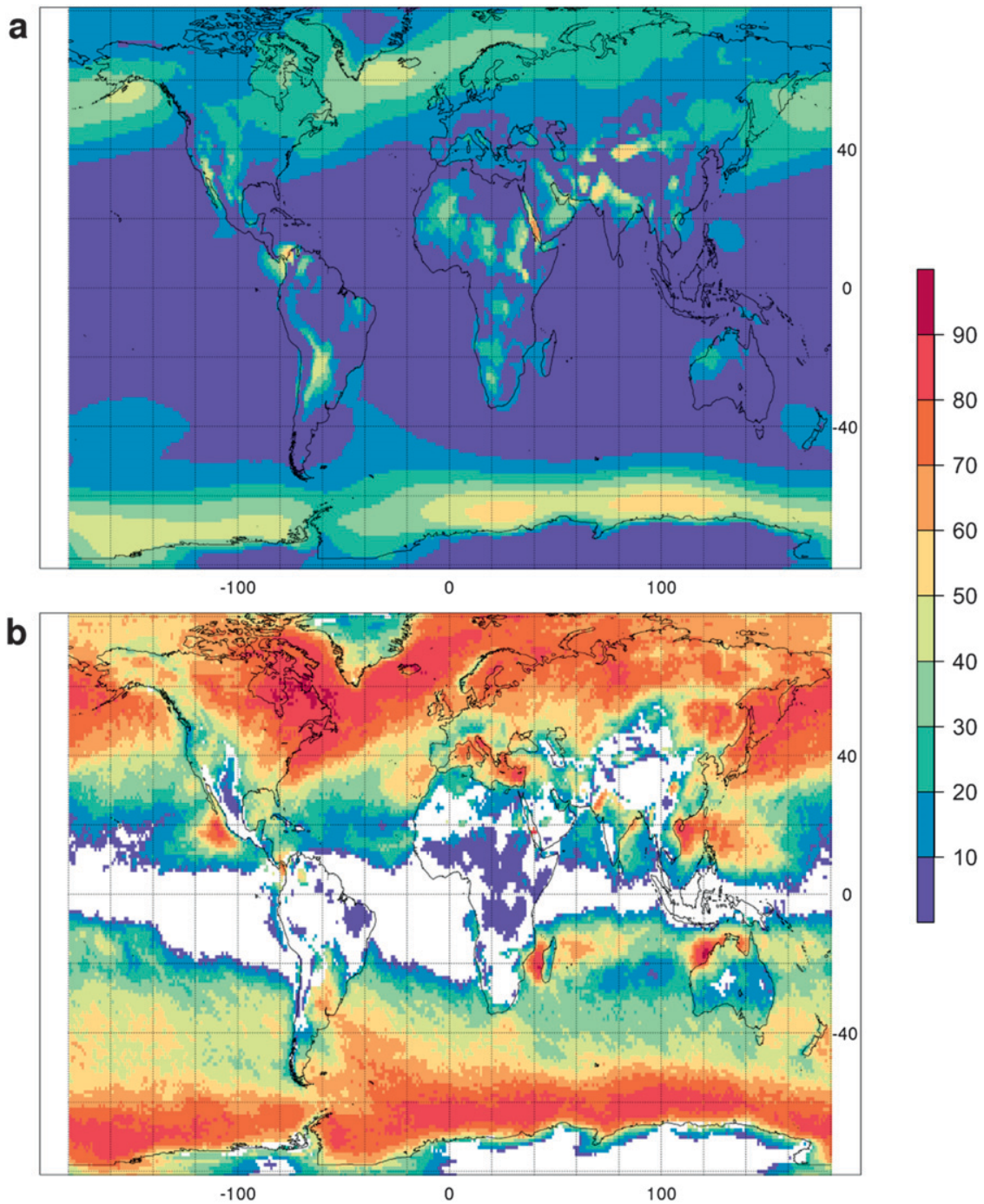

FIG. 4. (a) Relative frequency (\%) of cyclones in the ERA-Interim data (1989-2009). (b) Percentage $f$ of 6-hourly precipitation extremes occurring simultaneously with a cyclone at the same grid point. Grid points are masked in white if the relationship between cyclones and extreme precipitation events is statistically not highly significant.

topography (although this is minimized by only considering cyclone centers in areas where topography is below $1500 \mathrm{~m}$ ). Furthermore, there are local maxima, for example, over Africa, probably related to the formation of heat lows. Most of these features are well known from previous climatologies (e.g., Hoskins and Hodges 2002; Wernli and Schwierz 2006), although here the absolute cyclone frequency values are relatively high since weak depressions are also taken into account and the data are smoothed over 6-hourly time intervals (see section $2 b$ ).

\section{c. Coincidence of precipitation extremes and cyclones}

A cyclone is assumed to induce a precipitation extreme if both occur simultaneously at the same grid point. The percentage $f$ of extreme precipitation events coinciding with a cyclone can then be quantified at every grid point (see section $2 \mathrm{~b}$ ). If at a certain location $f$ is similar to the average cyclone frequency, the influence of cyclones on precipitation extremes is negligible. A statistical test based on bootstrapping is performed to identify grid points where this is the case (see section 2c). The geographical distribution of $f$ is shown in Fig. 4b. In the storm track regions, values are often larger than $80 \%$ and thus strongly exceed the climatological cyclone frequency (cf. Fig. 4a). These cyclone-related precipitation extremes affect densely populated regions, in particular over the northeastern United States, the United Kingdom, northern Europe, and Japan, where $f$ is on 
the order of $60 \%-80 \%$. Also near the cyclone frequency maximum east of the Andes, there is a local maximum of $f$ with values close to $70 \%$ near the Rio de la Plata estuary. Other regional maxima occur far away from the storm tracks and are associated with very low climatological cyclone frequencies. They are often located over the ocean, for example, west of Madagascar or off the northwestern Australian coast, but also extend to the adjacent land regions, in particular around the Mediterranean Sea, in eastern China, and over the Philippines and southeastern United States, where $f$ reaches $50 \%-$ $60 \%$ also over land. Several more equatorward maxima of $f$, for example, over the South China Sea, west of Central America, and northwest of Australia, are most probably associated with tropical cyclones (see also Lau et al. 2008; Knight and Davis 2009). The reduction of $f$ over the continents is likely due to the increasing importance of other mechanisms for triggering precipitation extremes such as mesoscale convection or orographic lifting (Smith et al. 2003). The importance of the latter is evident from the local minima of $f$, for example, at the Norwegian coast, at the west coast of New Zealand, and in the European Alps where orography is steep. In agreement with this argument, there is a regional maximum of $f$ over the west Siberian Plain, and lower values prevail in the surrounding mountainous regions. In the tropics there are large regions where there is no significant impact of cyclones on precipitation extremes. At these latitudes cyclones are generally rare and weak. The fact that these tropical regions often concur with areas where ERA-Interim does not capture well the timing of the precipitation extremes (cf. Fig. 3) indicates again that cyclone-induced precipitation extremes in the extratropics are better represented in the reanalysis compared to intense precipitation caused by tropical convection. Interestingly, over parts of Africa there is a significant negative relation between low pressure systems and precipitation extremes, suggesting that precipitation events do not coincide with strong continental heating (which favors the formation of heat lows). All together, Fig. 4b shows that the impact of cyclones on precipitation extremes is huge and highly significant in many regions all over the globe. It is not restricted to the main storm tracks, but rather is also of great importance in areas where cyclones are rare.

Qualitatively, the results presented in Fig. $4 b$ do not depend on the time scale of the precipitation events. If ERA-Interim precipitation time series are temporally smoothed with a 1-day or 3-day running average, and all events for which a low pressure system occurs within this extended period are associated with this cyclone (see section $2 \mathrm{~b}$ ), both cyclone frequency and $f$ increase, but there is still a significant difference between the two in many regions (not shown). The spatial patterns are very similar to the one shown in Fig. 4b for 6-hourly accumulated precipitation extremes. In midlatitudes and over the high-latitude oceans, almost all 3-day precipitation extremes coincide with a cyclone. Note, however, that for these 3-day events, the occurrence of the precipitation peak and the cyclone may not be simultaneous, making the causal relationship more uncertain.

The seasonal cycle of the percentage of precipitation extremes related to cyclones widely corresponds to the seasonality of the cyclone frequency (Fig. 5). It is stronger in the Northern than in the Southern Hemisphere storm track, in particular over the western Pacific. A pronounced seasonality of $f$ is found in the Mediterranean area, where most cyclones and the associated precipitation extremes occur during boreal winter. Tropical cyclones and the corresponding extreme precipitation events predominantly occur in the respective summer season, leading to a strong seasonality of $f$ over the North Atlantic west of Africa, the Philippine and South China Seas, parts of the tropical southwest Pacific and the Indian Ocean, as well as the North Pacific west of Central America.

\section{d. Properties of cyclones causing extreme precipitation}

In this section, not the precipitation events but the cyclone tracks affecting a specific grid point are used as a starting point for the statistical analysis. Two categories of such cyclone tracks can be distinguished: those that are associated with an extreme precipitation event at this location and those that are not. The percentage $\tilde{f}$ of the first category (cf. section $2 b$ ) is plotted in Fig. 6 . In the storm track regions where cyclones are frequent, $\tilde{f}$ is mostly around $10 \%$ or lower. Maxima of $\tilde{f}$ larger than $27 \%$ are found over the subtropical oceans. In these regions cyclones are rare, but these rare occurrences are associated relatively often with extreme precipitation. Especially with respect to the prediction of extreme precipitation events, it is interesting to know in which ways cyclones causing these events (first category) differ from those that are not (second category). Figure 7 shows the difference in two cyclone track properties between the two categories: the minimum core pressure along the track and the latitudinal displacement from the genesis point to the location of the extreme precipitation event. All values are normalized by the local wholesample standard deviation of the respective quantity, giving an idea of the magnitude of the difference relative to the overall variability. The minimum core pressure of cyclones of the first category, which is a measure for cyclone intensity, is slightly lower than for the second category in the exit regions of the Northern 

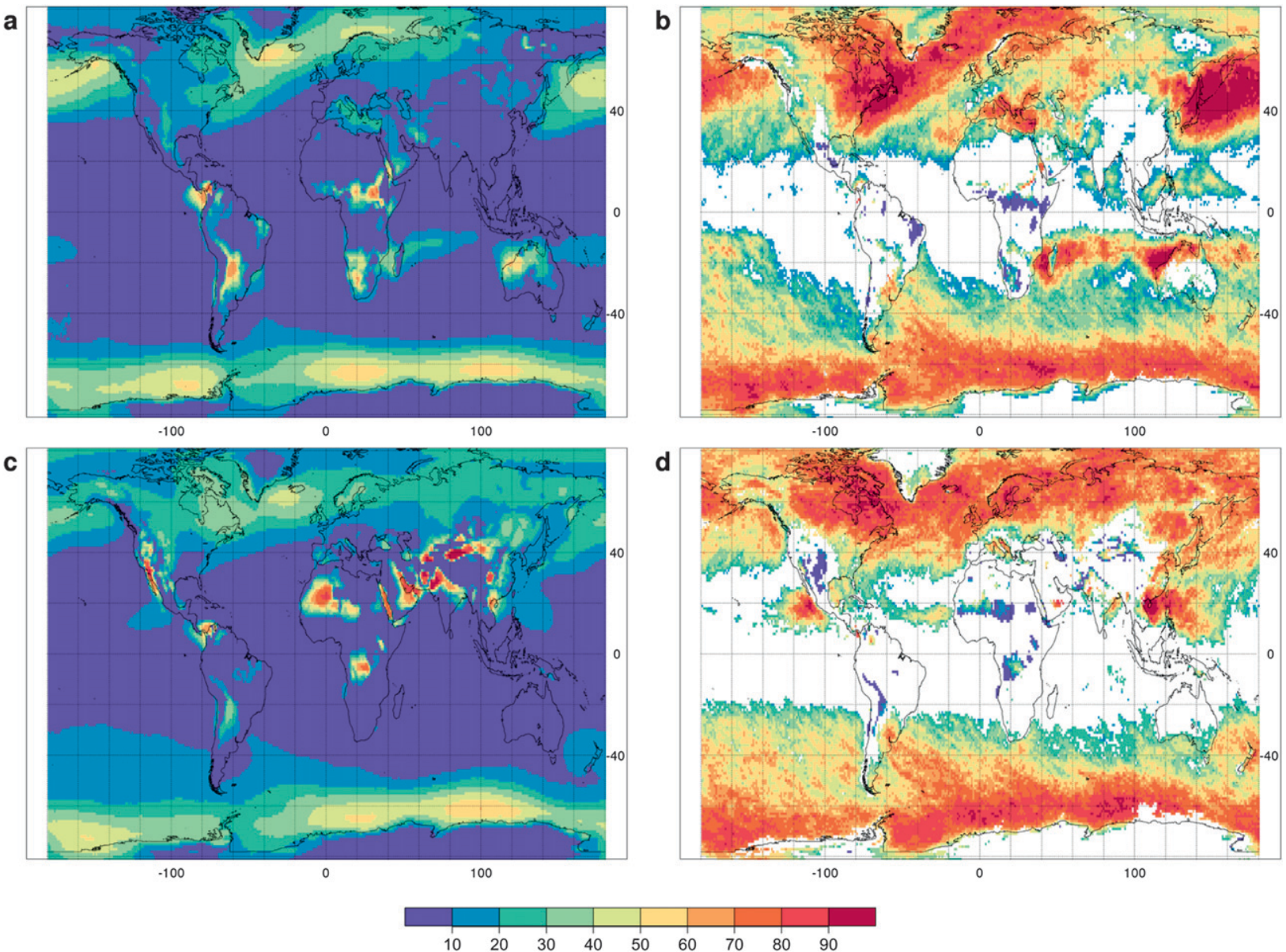

FIG. 5. Coincidence of cyclones and precipitation extremes in different seasons: relative cyclone frequency (\%) in (a) DJF and (c) JJA; percentage of precipitation extremes related to a cyclone in (b) DJF and (d) JJA. Grid points are masked in white if the relationship between cyclones and extreme precipitation events is statistically not highly significant. Note that the smaller number of events leads to slightly more noisy spatial structures compared to Fig. 4b.

Hemisphere storm tracks close to the U.S. and European west coasts and east of Greenland (Fig. 7a). However, in the genesis and intensification regions of the storm tracks, cyclones causing extreme precipitation are not substantially more intense than all other systems. This is a remarkable result since it indicates that in these regions cyclones associated with heavy precipitation are not "suspicious" in terms of their SLP intensity. In the Southern Hemisphere storm track and in parts of the tropics, precipitation extremes typically are associated with cyclones that are somewhat more intense than other low pressure systems in these regions. This signal is particularly strong near the Indian subcontinent, where the occurrence of precipitation extremes likely relates to the intensity of the monsoonal depression. The latitudinal displacement shown in Fig. 7b indicates that in several regions, such as on the eastern flank of the continents and at the entrance of the Northern Hemisphere storm tracks, cyclones causing extreme precipitation commonly have a more equatorward origin. This signal is strongest in the Caribbean area, where a more southerly genesis point relates to the typical pathway of North Atlantic tropical cyclones, but can also be found in more poleward regions along the U.S. coast (and also east of Japan). The latter might be associated with tropical cyclones undergoing extratropical transition (although the signal is not restricted to the summer and fall season; not shown) or northward-moving extratropical cyclones that have a greater moisture supply than storms moving eastward off the continent. In spite of these regionally consistent patterns, the magnitudes of all the differences shown in Fig. 7 are relatively small compared to the overall variability of the respective cyclone track properties. This is also the case for several other parameters like track length, longitudinal displacement, traveling speed, cyclone size, lifetime, and SLP decrease in the 


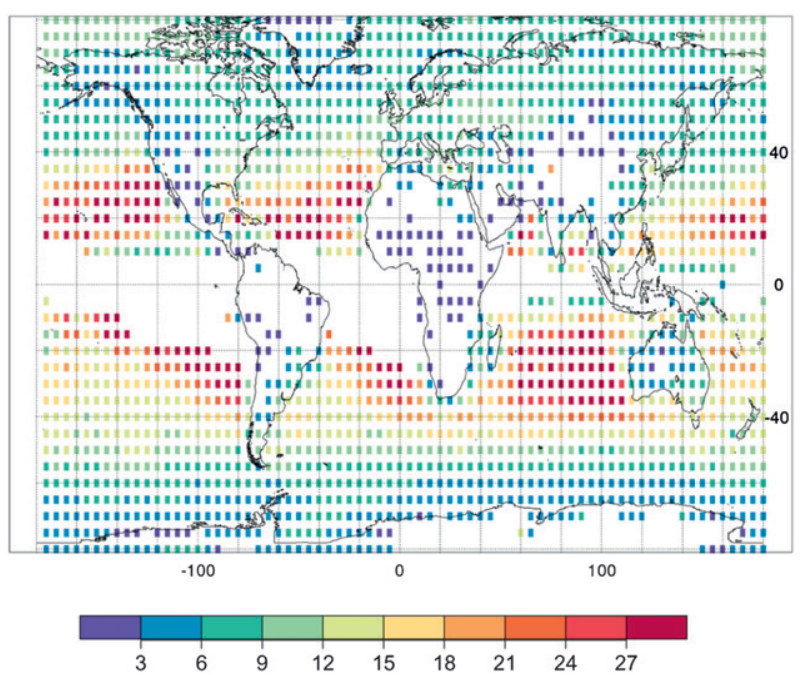

FIG. 6. Percentage $\tilde{f}$ of cyclones leading to a precipitation extreme at the respective grid point relative to all cyclones touching this point. This percentage is only calculated for every fifth grid point in latitude-longitude directions. Data are not shown where the relationship between cyclones and extreme precipitation events is statistically not highly significant (cf. Fig. 4b). Note that to improve visibility, plotting symbols are larger than the respective $1^{\circ} \times 1^{\circ}$ grid boxes.

$24 \mathrm{~h}$ prior to the arrival at the respective grid point (not shown). Hence, the reasons why one cyclone causes an extreme precipitation event and another does not often cannot be easily attributed to simple overall cyclone properties.

a
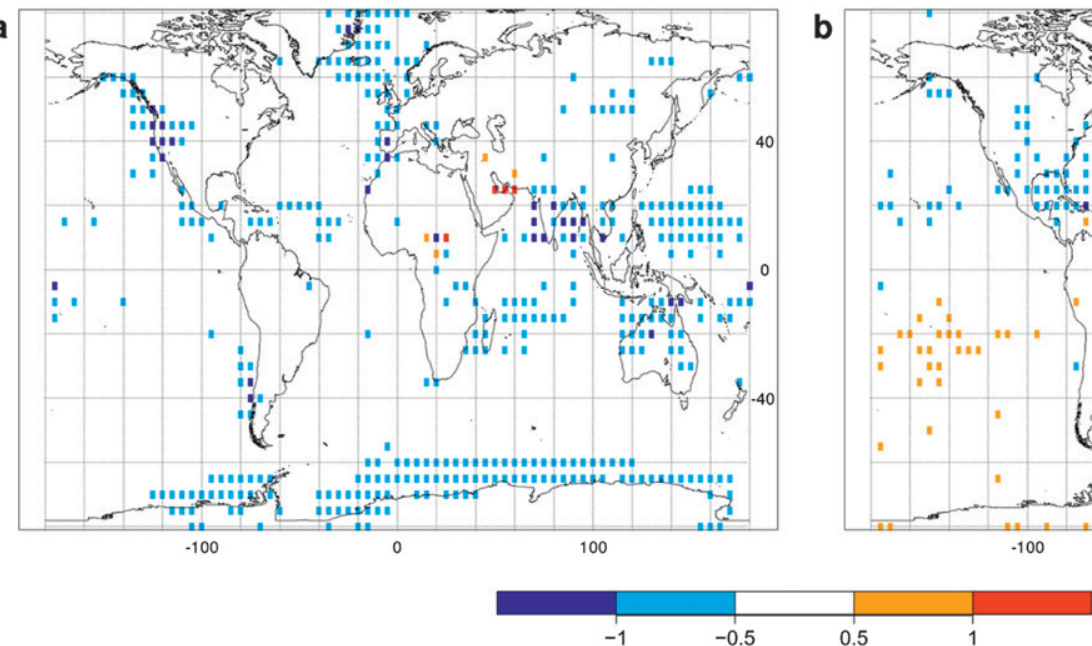

FIG. 7. Differences between (a) minimum core pressure and (b) latitudinal displacement relative to the genesis point (defined as the latitude of cyclogenesis minus the latitude of the extreme event) of cyclones causing an extreme precipitation event at the respective location and all other cyclones, shown for every fifth grid point in latitude-longitude directions. All fields are given in units of the local whole sample standard deviation of the respective quantity. Data are not shown where the relationship between cyclones and extreme precipitation events is statistically not highly significant (cf. Fig. 4b). Note that to improve visibility, plotting symbols are larger than the respective $1^{\circ} \times 1^{\circ}$ grid boxes.

\section{Conclusions}

In this study, ERA-Interim data have been used for quantifying the relevance of cyclones for extreme precipitation events. A comparison with CMORPH satellite estimates has shown that the ERA-Interim precipitation extremes, though their magnitude is often too small, properly represent the timing of the extreme events in major parts of the globe. They are thus well suited for investigating possible interrelations with the occurrence of cyclones. In many regions, not restricted to the main storm tracks, cyclones have been shown to be associated with a huge percentage of the precipitation extremes. This percentage might be even higher if other than the local influence of cyclones would be taken into account. In future research, remote effects of cyclones on extreme precipitation events, for example, via elongated frontal systems, may be considered additionally. Furthermore, the importance of tropical cyclones may be investigated more specifically and in more detail (see again Lau et al. 2008; Knight and Davis 2009). The results of this study show that the prediction of heavy precipitation and floods in weather forecasts often depends crucially on the accurate prediction of the associated cyclone track. Feature-based forecast methods (i.e., methods based on the identification of specific atmospheric flow features like cyclones) may thus be of great potential value (cf. Carley et al. 2011). Nevertheless, the relatively low fraction $\tilde{f}$ of cyclones leading to precipitation extremes and the fact that these cyclones are often not clearly distinguishable with the help of attributes

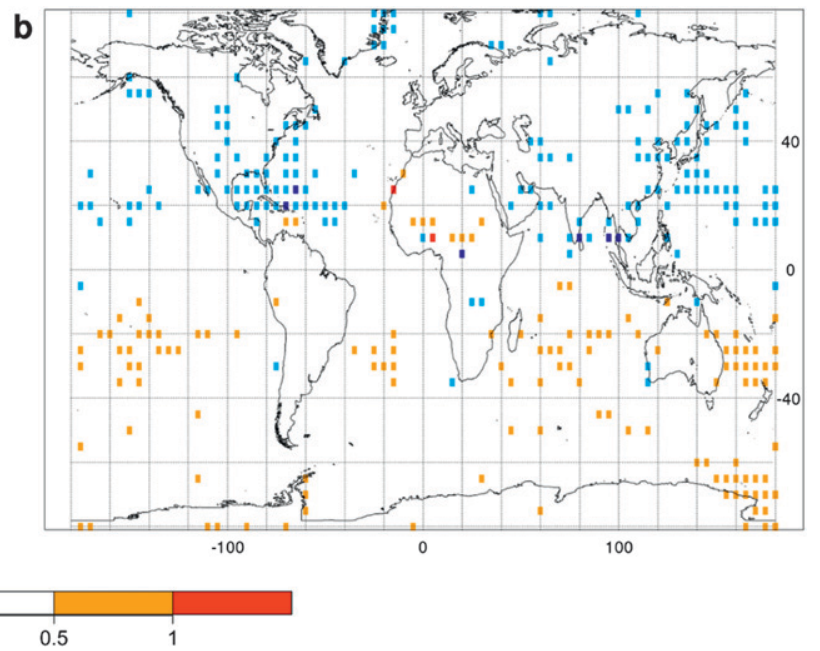

b 
like their intensity (cf. section 3d) indicate that simple forecast rules that are only based on cyclone occurrence can most probably not be established. Often the complex interplay of several factors and mesoscale substructures leads to heavy precipitation, and the presence of a cyclone, though important, is only one of these factors.

The feature-based perspective on the meteorological mechanisms of precipitation extremes obtained here is important for understanding and projecting changes in these events due to global warming, in particular on regional scales. Such changes can be due to the increasing atmospheric moisture content (Allen and Ingram 2002; Trenberth et al. 2003; Pall et al. 2007; Allan and Soden 2008), but can also be caused by variations in the dynamical forcing mechanisms. In many regions where a large percentage of precipitation extremes is related to cyclones, their future changes are specifically sensitive to variations in the abundance of these weather systems and the location of storm tracks.

Furthermore, it will be an essential next step to validate the spatial patterns of the coincidence of cyclones and precipitation extremes from present-day climate model simulations against the results obtained here for the reanalysis dataset. Such a process-based model validation (cf. Schaller et al. 2011) will provide important information about the proper representation of key mechanisms in the models for simulating precipitation extremes. Finally, the importance of cyclones for the occurrence of extreme precipitation events and the fact that it is nevertheless complicated to assess if and why a specific cyclone causes an extreme event motivate further process-based studies on precipitation formation in these weather systems (e.g., Wang et al. 2010; Field et al. 2011; Joos and Wernli 2012; Schäfler et al. 2011).

Acknowledgments. MeteoSwiss and ECMWF are acknowledged for giving access to ERA-Interim data, and the Climate Prediction Center at NOAA for providing CMORPH precipitation estimates. We thank M. Sprenger (ETH Zurich) for technical support with the cyclone identification algorithm as well as H. Joos, M. Böttcher, and H. C. Davies (ETH Zurich) for helpful comments. Comments by three anonymous reviewers have helped to improve the manuscript. The software package $\mathrm{R}$ ( $\mathrm{R}$ Development Core Team 2010) has been used for producing the analyses and graphics for this study.

\section{REFERENCES}

Allan, R. P., and B. J. Soden, 2008: Atmospheric warming and the amplification of precipitation extremes. Science, 321, 14811484, doi:10.1126/science.1160787

Allen, M. R., and W. J. Ingram, 2002: Constraints on future changes in climate and the hydrological cycle. Nature, 419, 224-232.
Bengtsson, L., K. I. Hodges, and N. Keenlyside, 2009: Will extratropical storms intensify in a warming climate? J. Climate, 22, 2276-2301.

Browning, K. A., 1986: Conceptual models of precipitation systems. Wea. Forecasting, 1, 23-41.

Carley, J. R., B. R. J. Schwedler, M. E. Baldwin, R. J. Trapp, J. Kwiatkowski, J. Logsdon, and S. J. Weiss, 2011: A proposed model-based methodology for feature-specific prediction for high-impact weather. Wea. Forecasting, 26, 243-248.

Champion, A. J., K. I. Hodges, L. O. Bengtsson, N. S. Keenlyside, and M. Esch, 2011: Impact of increasing resolution and a warmer climate on extreme weather from Northern Hemisphere extratropical cyclones. Tellus, 63A, 893-906, doi:10.1111/ j.1600-0870.2011.00538.x.

Dee, D. P., and Coauthors, 2011: The ERA-Interim reanalysis: Configuration and performance of the data assimilation system. Quart. J. Roy. Meteor. Soc., 137, 553-597, doi:10.1002/qj.828.

Dulière, V., Y. Zhang, and E. P. Salathé Jr., 2011: Extreme precipitation and temperature over the U.S. Pacific Northwest: A comparison between observations, reanalysis data, and regional models. J. Climate, 24, 1950-1964.

Easterling, D. R., G. A. Meehl, C. Parmesan, S. A. Changnon, T. R. Karl, and L. O. Mearns, 2000: Climate extremes: Observations, modeling, and impacts. Science, 289, 2068-2074, doi:10.1126/ science.289.5487.2068.

Field, P. R., and R. Wood, 2007: Precipitation and cloud structure in midlatitude cyclones. J. Climate, 20, 233-254.

A. Bodas-Salcedo, and M. E. Brooks, 2011: Using model analysis and satellite data to assess cloud and precipitation in midlatitude cyclones. Quart. J. Roy. Meteor. Soc., 137, 15011515, doi:10.1002/qj.858.

Hoskins, B. J., and K. I. Hodges, 2002: New perspectives on the Northern Hemisphere winter storm tracks. J. Atmos. Sci., 59, 1041-1061.

Joos, H., and H. Wernli, 2012: Influence of microphysical processes on the potential vorticity development in a warm conveyor belt: A case-study with the limited-area model COSMO. Quart. J. Roy. Meteor. Soc., 138, 407-418, doi:10.1002/qj.934.

Joyce, R. J., J. E. Janowiak, P. A. Arkin, and P. Xie, 2004: CMORPH: A method that produces global precipitation estimates from passive microwave and infrared data at high spatial and temporal resolution. J. Hydrometeor., 5, 487-503.

Kahana, R., B. Ziv, Y. Enzel, and U. Dayan, 2002: Synoptic climatology of major floods in the Negev Desert, Israel. Int. J. Climatol., 22, 867-882, doi:10.1002/joc.766.

Kenyon, J., and G. C. Hegerl, 2010: Influence of modes of climate variability on global precipitation extremes. J. Climate, 23, $6248-6262$.

Knight, D. B., and R. E. Davis, 2009: Contribution of tropical cyclones to extreme rainfall events in the southeastern United States. J. Geophys. Res., 114, D23102, doi:10.1029/2009JD012511.

Koenker, R., cited 2011: Quantreg: Quantile regression. R package version 4.69. [Available online at http://CRAN.R-project.org/ package $=$ quantreg. $]$

Lau, K.-M., Y. P. Zhou, and H.-T. Wu, 2008: Have tropical cyclones been feeding more extreme rainfall? J. Geophys. Res., 113, D23113, doi:10.1029/2008JD009963.

Lionello, P., and F. Giorgi, 2007: Winter precipitation and cyclones in the Mediterranean region: Future climate scenarios in a regional simulation. Adv. Geosci., 12, 153-158.

Maraun, D., T. J. Osborn, and H. W. Rust, 2011: The influence of synoptic airflow on UK daily precipitation extremes. Part I: Observed spatio-temporal relationships. Climate Dyn., 36, 261-275. 
Meehl, G. A., J. M. Arblaster, and C. Tebaldi, 2005: Understanding future patterns of increased precipitation intensity in climate model simulations. Geophys. Res. Lett., 32, L18719, doi:10.1029/ 2005 GL023680.

O'Gorman, P. A., and T. Schneider, 2009a: Scaling of precipitation extremes over a wide range of climates simulated with an idealized GCM. J. Climate, 22, 5676-5685.

_ and _ 2009b: The physical basis for increases in precipitation extremes in simulations of 21st-century climate change. Proc. Natl. Acad. Sci. USA, 106, 14 773-14 777, doi:10.1073/ pnas.0907610106.

Pall, P., M. R. Allen, and D. A. Stone, 2007: Testing the ClausiusClapeyron constraint on changes in extreme precipitation under $\mathrm{CO}_{2}$ warming. Climate Dyn., 28, 351-363.

— T. Tina, D. A. Stone, P. A. Stott, T. Nozawa, A. G. J. Hilberts, D. Lohmann, and M. R. Allen, 2011: Anthropogenic greenhouse gas contribution to flood risk in England and Wales in autumn 2000. Nature, 470, 382-386, doi:10.1038/nature09762.

Portnoy, S., and R. Koenker, 1997: The Gaussian hare and the Laplacian tortoise: Computability of squared-error versus absolute error estimates. Stat. Sci., 12, 279-296.

R Development Core Team, cited 2010: R: A language and environment for statistical computing. R Foundation for Statistical Computing, Vienna, Austria. [Available online at http://www. R-project.org/.]

Raible, C. C., M. Yoshimori, T. F. Stocker, and C. Casty, 2007: Extreme midlatitude cyclones and their implications for precipitation and wind speed extremes in simulations of the Maunder Minimum versus present day conditions. Climate Dyn., 28, 409-423.

Rappaport, E. N., 2000: Loss of life in the United States associated with recent Atlantic tropical cyclones. Bull. Amer. Meteor. Soc., 81, 2065-2073.
Schäfler, A., A. Dörnbrack, H. Wernli, C. Kiemle, and S. Pfahl, 2011: Airborne lidar observations in the inflow region of a warm conveyor belt. Quart. J. Roy. Meteor. Soc., 137, $1257-$ 1272, doi:10.1002/qj.827.

Schaller, N., I. Mahlstein, J. Cermak, and R. Knutti, 2011: Analyzing precipitation projections: A comparison of different approaches to climate model evaluation. J. Geophys. Res., 116, D10118, doi:10.1029/2010JD014963.

Smith, R. B., Q. Jiang, M. G. Fearon, P. Tabary, M. Dorninger, J. D. Doyle, and R. Benoit, 2003: Orographic precipitation and air mass transformation: An Alpine example. Quart. J. Roy. Meteor. Soc., 129, 433-454, doi:10.1256/qj.01.212.

Trenberth, K. E., A. Dai, R. M. Rasmussen, and D. B. Parsons, 2003: The changing character of precipitation. Bull. Amer. Meteor. Soc., 84, 1205-1217.

Ulbrich, U., T. Brücher, A. H. Fink, G. C. Leckebusch, A. Krüger, and J. G. Pinto, 2003: The central European floods of August 2002: Part 2 - Synoptic causes and considerations with respect to climatic change. Weather, 58, 434-442.

Wang, Z., M. T. Montgomery, and T. J. Dunkerton, 2010: Genesis of pre-Hurricane Felix (2007). Part II: Warm core formation, precipitation evolution, and predictability. J. Atmos. Sci., 67, 1730-1744.

Wernli, H., and H. C. Davies, 1997: A Lagrangian-based analysis of extratropical cyclones. I: The method and some applications. Quart. J. Roy. Meteor. Soc., 123, 467-489.

_ , and C. Schwierz, 2006: Surface cyclones in the ERA-40 dataset (1958-2001). Part I: Novel identification method and global climatology. J. Atmos. Sci., 63, 2486-2507.

Yiou, P., and M. Nogaj, 2004: Extreme climatic events and weather regimes over the North Atlantic: When and where? Geophys. Res. Lett., 31, L07202, doi:10.1029/2003GL019119. 